\title{
Cord-Blood Transplants from Unrelated Donors in Patients with Hurler's Syndrome
}

\author{
Susan L. Staba, M.D., Maria L. Escolar, M.D., Michele Poe, Ph.D., \\ Young Kim, M.S., Paul L. Martin, M.D., Ph.D., Paul Szabolcs, M.D., \\ June Allison-Thacker, R.N., Susan Wood, P.N.P., David A. Wenger, Ph.D., \\ Pablo Rubinstein, M.D., John J. Hopwood, Ph.D., William Krivit, M.D., Ph.D., \\ and Joanne Kurtzberg, M.D.
}

ABSTRACT

From the Pediatric Stem Cell Transplant Program, Duke University Medical Center Durham, N.C. (S.L.S., P.L.M., P.S., J.A.-T., S.W., J.K.); the Center for Development and Learning (M.L.E.) and the Frank Porter Graham Child Development Center (M.P.) University of North Carolina School of Medicine, Chapel Hill; Emmes Corporation, Rockville, Md. (Y.K.); Jefferson Medical College, Philadelphia (D.A.W.); the Placental Blood Program, New York Blood Center, New York (P.R.); Women's and Children's Hospital, Adelaide, Australia (J.J.H.); and the University of Minnesota School of Medicine, Minneapolis (W.K.). Address reprint requests to Dr. Staba at Box 3350 Duke University Medical Center, Durham NC 27710, or at staba001@mc.duke.edu.

N Engl J Med 2004;350:1960-9.

Copyright @ 2004 Massachusetts Medical Society.

\begin{abstract}
BACK GROUND
Hurler's syndrome (the most severe form of mucopolysaccharidosis type I) causes progressive deterioration of the central nervous system and death in childhood. Allogeneic bone marrow transplantation before the age of two years halts disease progression and prolongs life, but many children lack a bone marrow donor. We investigated the feasibility of using cord-blood transplants from unrelated donors and a myeloablative preparative regimen that did not involve total-body irradiation in young children with Hurler's syndrome.
\end{abstract}

\section{METHODS}

Between December 1995 and October 2002, 20 consecutive children with Hurler's syndrome received busulfan, cyclophosphamide, and antithymocyte globulin before receiving cord-blood transplants from unrelated donors. The children were subsequently evaluated for engraftment, adverse effects, and effects on disease symptoms.

\section{RESULTS}

Cord-blood donors had normal $\alpha$-L-iduronidase activity (mean number of cells, $10.53 \times 10^{7}$ per kilogram of body weight) and were discordant for up to three of six HLA markers. Neutrophil engraftment occurred a median of 24 days after transplantation. Five patients had grade II or grade III acute graft-versus-host disease; none had extensive chronic graft-versus-host disease. Seventeen of the 20 children were alive a median of 905 days after transplantation, with complete donor chimerism and normal peripheral-blood $\alpha$-L-iduronidase activity (event-free survival rate, 85 percent). Transplantation improved neurocognitive performance and decreased somatic features of Hurler's syndrome.

\section{CONCLUSIONS}

Cord blood from unrelated donors appears to be an excellent source of stem cells for transplantation in patients with Hurler's syndrome. Sustained engraftment can be achieved without total-body irradiation. Cord-blood transplantation favorably altered the natural history of Hurler's syndrome and thus may be important to consider in young children with this form of the disease. 
H

URLER'S SYNDROME (THE MOST SEvere form of mucopolysaccharidosis type I), an autosomal recessive metabolic storage disease caused by a deficiency of $\alpha$-L-iduronidase, results in the accumulation of heparan and dermatan sulfate substrates (glycosaminoglycans) in various tissues. ${ }^{1,2}$ Severe phenotypes, in which symptoms begin by two years of age, are characterized by severe, progressive deterioration of the central nervous system, cardiac disease, skeletal abnormalities, corneal clouding, hepatomegaly, and death in childhood. ${ }^{1-7}$ Bone marrow transplantation can prevent the progression of selected heritable enzyme deficiencies and provides maximal benefit when performed early in life. ${ }^{8}$ More than 200 patients with Hurler's syndrome have undergone allogeneic bone marrow transplantation since 1980.3,4,7-17 Donor stem cells deliver enzyme inside and outside the blood compartment, arresting the progression of the disease and improving overall survival. 2,5-17 Unfortunately, many children who might benefit from transplantation lack an appropriately matched donor.9,11,13,14,17 Because banked umbilical-cord blood from unrelated donors with partial HLA mismatches can provide donor stem cells for children with cancer who lack suitable bone marrow donors, ${ }^{18-20}$ we used cord blood from unrelated donors as the source of hematopoietic stem cells for transplantation in children with Hurler's syndrome.

\section{METHODS}

\section{PATIENTS}

Between December 28, 1995, and October 16, 2002, 20 consecutive children with Hurler's syndrome who were referred to Duke University Medical Center for transplantation and who lacked HLAmatched, related bone marrow donors who were not carriers of the disease received cord-blood transplants from unrelated donors. The diagnosis of Hurler's syndrome was confirmed on the basis of the activity of $\alpha$-L-iduronidase in peripheral-blood leukocytes and the clinical phenotype. ${ }^{21}$ All patients were enrolled in a phase 1 and 2 study of cord-blood transplantation for the treatment of nonmalignant diseases approved by the institutional review board of Duke University. The parents of each patient provided written informed consent before enrollment.

\section{SELECTION OF DONORS}

Searches for cord-blood units from unrelated donors were conducted with the use of intermediate- resolution typing for HLA class I (A and B) and highresolution typing for HLA-DRB1. The unit of cord blood with the highest number of nucleated cells (minimum, $3 \times 10^{7}$ per kilogram of body weight) that matched at least three of six HLA loci was selected. Units were tested for leukocyte $\alpha$-L-iduronidase activity, ${ }^{22}$ and those with high-normal activity were selected.

\section{TRANSPLANTATION PROCEDURE}

Cryopreserved units of cord blood were thawed and processed in a standard fashion. ${ }^{23}$ The total numbers of nucleated cells, clonal hematopoietic progenitor cells, and CD34+ cells were counted; ABO and $\mathrm{Rh}$ typing was performed; the viability of the cells was assessed; and bacterial and fungal cultures were obtained before the infusion.

\section{CONDITIONING REGIMEN}

All patients were prepared for transplantation by receiving 16 doses of busulfan (20 to $40 \mathrm{mg}$ per square meter of body-surface area orally, with the dose based on age) from days 9 through 6 before transplantation; 4 doses of cyclophosphamide (50 mg per kilogram of body weight given intravenously) from days 5 through 2 before transplantation; and 3 doses of antithymocyte globulin (PharmaciaUpjohn; $30 \mathrm{mg}$ per kilogram given intravenously from days 3 through 1 before transplantation). The pharmacokinetics of busulfan were assessed after the first dose, and subsequent doses were adjusted to maintain a steady-state concentration of 600 to 900 ng per milliliter. ${ }^{24}$ One patient required an increase in the dose, and 11 patients required a decrease. Patients received phenytoin for prophylaxis against seizures during treatment; busulfan and mesna were also given for prophylaxis against hemorrhagic cystitis during cyclophosphamide therapy. Radiation therapy was not used as part of the conditioning regimen.

\section{PROPHYLAXIS AGAINST AND TREATMENT OF GRAFT-VERSUS-HOST DISEASE}

All children received cyclosporine for nine months and methylprednisolone for two to three months as prophylaxis against graft-versus-host disease (GVHD). ${ }^{18}$ The severity of acute GVHD was scored with the use of standard criteria. ${ }^{25}$ Patients with grade I acute GVHD were treated with topical creams, a small escalation in the dose of systemic methylprednisolone, or both. Patients with moderate acute GVHD received four pulsed doses of methylprednisolone $(500 \mathrm{mg}$ per square meter given in- 
travenously every 12 hours) before treatment was switched to tacrolimus, alone or in combination with dacliximab (Hoffmann-LaRoche).

\section{SUPPORTIVE CARE}

All patients were kept in reverse isolation rooms with high-energy particulate air filtration. Standard prophylaxis against Pneumocystis carinii, viral, and fungal infections was used. Empirical treatment with broad-spectrum antibiotics was started with the first episode of febrile neutropenia and continued through engraftment. Intravenous immune globulin was administered weekly through day 100 . A continuous infusion of low-dose heparin was used as prophylaxis against veno-occlusive disease. $\mathrm{Pa}$ tients received transfusions of leukocyte-depleted, irradiated, packed red cells and platelets. Filgrastim (Amgen; $10 \mu \mathrm{g}$ per kilogram per day) was administered daily from the day of transplantation (day 0) through engraftment. Engraftment was defined by an absolute neutrophil count of at least 500 donor cells per cubic millimeter on three consecutive days.

\section{POST-TRANSPLANTATION EVALUATION}

Patients were evaluated every 6 to 12 months by multiple pediatric subspecialists in developmental pediatrics, ophthalmology, audiology, cardiology (to obtain echocardiograms and provide follow-up), pulmonology, and orthopedics (to obtain hip and spine films and provide follow-up). The Cobb method was used to quantify the degree of kyphoscoliosis. Hip films were evaluated for subluxation, acetabular coverage, and dysplasia. The need for orthopedic surgery was determined on the basis of radiographic and clinical findings. Neurocognitive function was evaluated by the Program for the Study of Neurodevelopmental Function in Rare Disorders (Center for Development and Learning, University of North Carolina, Chapel Hill). Patients less than three years of age were assessed with the Bayley Scales of Infant Development, the Clinical Adaptive Test-Clinical Linguistic Auditory Milestone Scale in Early Cognitive Assessment, and the Mullen Scales of Early Learning. Patients three years of age or older were assessed with the Mullen Scales of Early Learning and the Differential Abilities Scales. Standard scores, T scores, and developmental quotients were converted to age-equivalent scores to allow comparisons of results among various tests.

\section{STATISTICAL ANALYSIS}

The probability of event-free survival was calculated according to the Kaplan-Meier method. The prob- abilities of all other events were calculated on the basis of their cumulative incidence, with engraftment, the occurrence of acute GVHD, and death as competing events. ${ }^{26}$ Adverse events were defined as death, autologous recovery, and graft failure. Each patient's developmental course was assessed with the use of the hierarchical linear model, which depicts changes in cognitive function over time. This type of model allows for missing data and irregular evaluation times. The contribution to the estimate of the slope and intercept is greater for patients with more data points than for those with fewer data points. Linear and quadratic polynomial terms are included to allow for nonlinear changes. The cutoff date for data analysis was September 1, 2003.

\section{RESULTS}

\section{CHARACTERISTICS OF THE PATIENTS}

From December 1995 through October 2002, 20 children (10 boys and 10 girls) received cord-blood transplants from unrelated donors. The median weight of the children was $12 \mathrm{~kg}$ (range, 5 to 15). The median age was 11 months (range, prenatal to 29 months) at diagnosis and 16 months (range, 2 to 33) at transplantation (Table 1). Five patients required ventriculoperitoneal shunts before transplantation, but none required them after transplantation.

\section{SELECTION OF UNITS FOR TRANSPLANTATION}

Units of umbilical-cord blood were matched to the patient's HLA phenotype at three to six loci (Table 1). Ten patients received units with major $\mathrm{ABO}$-bloodgroup incompatibilities. The mean number of nucleated cells in units selected for transplantation (before cryopreservation) was $10.53 \times 10^{7}$ per kilogram (range, $3.38 \times 10^{7}$ to $20.95 \times 10^{7}$ ), whereas the mean number of cells infused (after thawing) was $8.34 \times 10^{7}$ per kilogram (range, $1.91 \times 10^{7}$ to $20.90 \times 10^{7}$ ), and the mean number of CD34+ cells infused was $2.51 \times 10^{5}$ per kilogram (range, $0.66 \times 10^{5}$ to $104.75 \times 10^{5}$ ) (Table 1 ).

\section{EN GRAFTMENT}

Neutrophil and platelet engraftment occurred a median of 24 days (range, 10 to 39) and 56 days (range, 28 to 216), respectively, after transplantation (Table 2 and Fig. $1 \mathrm{~A}$ and 1B). Red-cell and platelet transfusions were no longer required after a median interval of 48 days (range, 20 to 67) and 55 days (range, 20 to 113), respectively, with patients requiring a median of 10 transfusions of packed red cells 


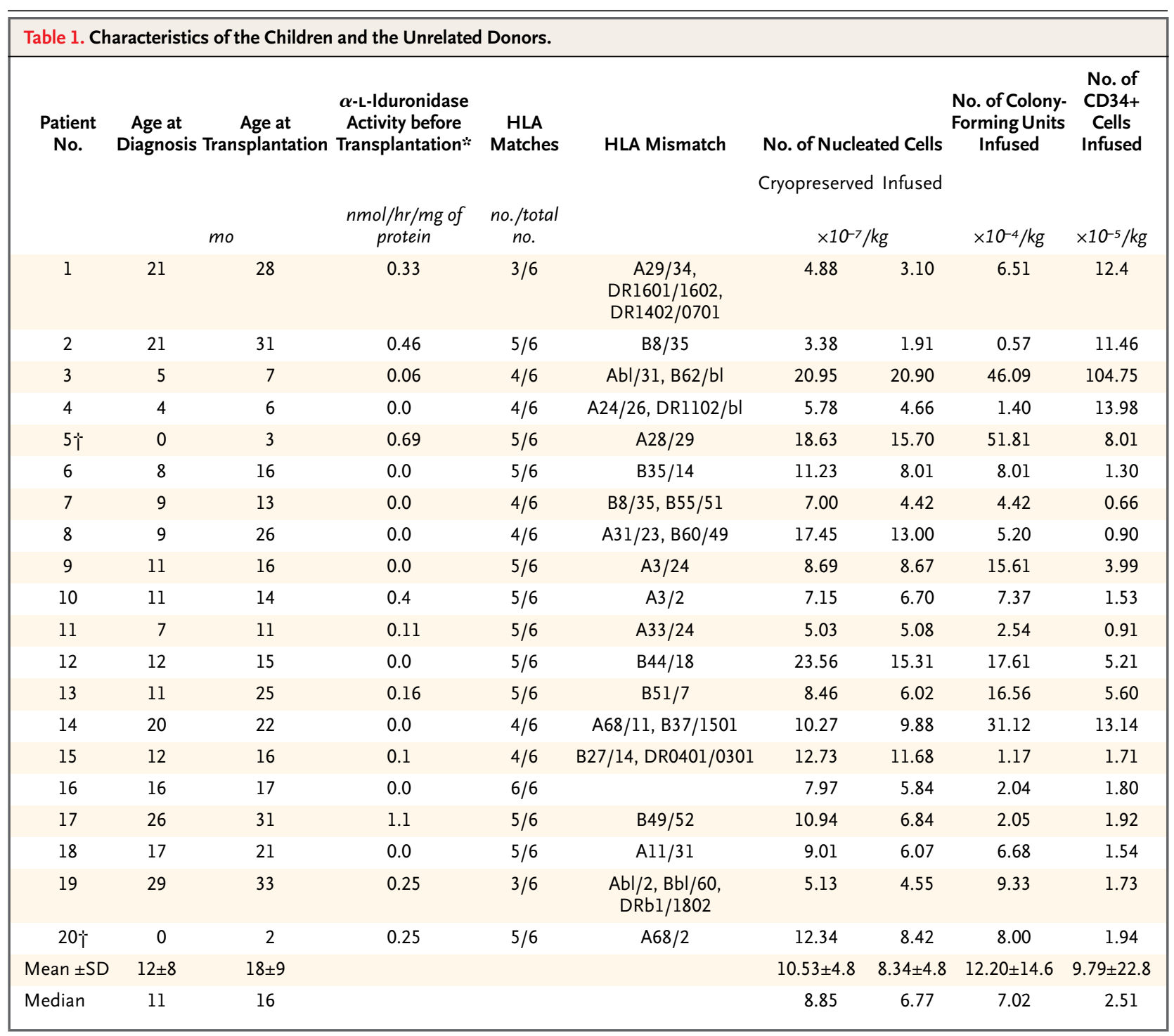

$* \alpha$-L-Iduronidase activity was measured in peripheral-blood leukocytes. The normal range is 30 to $70 \mathrm{nmol}$ per hour per milligram of protein. $\dagger$ The patient had family members with Hurler's syndrome and received a diagnosis prenatally.

and 28 platelet transfusions in the interim. As of the last follow-up evaluation, all 17 surviving patients continued to have complete donor chimerism and normal peripheral-blood $\alpha$-L-iduronidase activity (Table 2).

\section{IMMUNE RECONSTITUTION}

Cellular and humoral immune function was assessed quarterly for the first year after transplantation and yearly thereafter. CD4+ cell counts exceeded 100 per cubic millimeter at three months, 200 per cubic millimeter at six months, and 400 per cubic millimeter at nine months. The degree of prolifera- tion in response to phytohemagglutinin and the absolute lymphocyte count were normal by nine months after transplantation. All children were immunized with age-appropriate killed- and live-virus vaccines after normalization of immune function, without adverse reactions.

\section{GRAFT-VERSUS-HOST DISEASE}

The overall probability of moderate-to-severe acute GVHD was 25 percent a median of 11 days (range, 8 to 35) after transplantation (Table 2). Limited, chronic GVHD of the skin developed in two patients, whereas none had extensive chronic GVHD. 


\begin{tabular}{|c|c|c|c|c|c|c|c|c|c|c|}
\hline \multirow[t]{2}{*}{$\begin{array}{l}\text { Patient } \\
\text { No. }\end{array}$} & \multirow[t]{2}{*}{$\begin{array}{l}\text { Neutrophil } \\
\text { Engraftment }\end{array}$} & \multirow[t]{2}{*}{$\begin{array}{c}\text { Platelet } \\
\text { Engraftment }\end{array}$} & \multicolumn{2}{|c|}{ Chimerism } & \multirow{3}{*}{$\begin{array}{l}\boldsymbol{\alpha} \text {-L-Iduron- } \\
\text { idase } \\
\text { Activityî } \\
\\
\mathrm{nmol} / \mathrm{hr} / \mathrm{mg} \\
\text { of protein }\end{array}$} & \multicolumn{3}{|c|}{ Acute GVHD } & \multirow[t]{2}{*}{$\begin{array}{l}\text { Chronic } \\
\text { GVHD }\end{array}$} & \multirow[t]{2}{*}{$\begin{array}{l}\text { Event-free } \\
\text { Survival } \%\end{array}$} \\
\hline & & & Day 10 & $1 \mathrm{Yr}$ & & Grade & Site & Day & & \\
\hline & \multicolumn{2}{|c|}{ day } & \multicolumn{2}{|c|}{ percent } & & & & & & day \\
\hline 1 & 34 & 82 & 100 & 100 & 31.4 & 1 & Skin & 9 & 0 & 2817 \\
\hline 2 & 39 & NE & & & & II & GI tract & 18 & NE & Died on day 90 \\
\hline 3 & 12 & 28 & 100 & 100 & 89.3 & 1 & Skin & 20 & 0 & 2410 \\
\hline 4 & 25 & 61 & 100 & 100 & 69.6 & 1 & Skin & 7 & 0 & 2220 \\
\hline 5 & 10 & 33 & 100 & 100 & 61.4 & 0 & & & 0 & 1815 \\
\hline 6 & 18 & 81 & 100 & 100 & 48.5 & 0 & & & 0 & 1747 \\
\hline 7 & NE & & & & & & & & & Died on day 32 \\
\hline 8 & 30 & 74 & 100 & 100 & 74.4 & I & Skin & 8 & 0 & 1487 \\
\hline 9 & 24 & 90 & 100 & 100 & 105.8 & 1 & Skin & 35 & 0 & 1481 \\
\hline 10 & 23 & 66 & 100 & 100 & 51.9 & 0 & & & 0 & 1248 \\
\hline 11 & 24 & 65 & 100 & 100 & 59.3 & 1 & Skin & 17 & 0 & 905 \\
\hline 12 & 21 & 67 & $>99$ & $>99$ & 60.0 & III & Skin, GI tract & 8 & 0 & 814 \\
\hline 13 & 21 & 71 & 100 & 100 & 57.8 & 1 & Skin & 9 & 0 & 809 \\
\hline 14 & 15 & 44 & $>99$ & $>99$ & 94.9 & I & Skin & 28 & 0 & 751 \\
\hline 15 & 30 & 216 & $>99$ & $>99$ & 51.1 & II & Skin & 8 & 0 & 674 \\
\hline 16 & 30 & 66 & $>99$ & $>99$ & 59.6 & 1 & Skin & 13 & 0 & 542 \\
\hline 17 & 28 & 88 & 100 & 100 & 39.3 & II & Skin & 11 & Limited (skin) & 541 \\
\hline 18 & 26 & 61 & $>99$ & $>99$ & 41.7 & III & Skin, GI tract & 11 & Limited (skin) & 480 \\
\hline 19 & $\mathrm{NE}$ & & & & 44.6 & & & & & Died on day 218 \\
\hline 20 & 19 & 47 & $>99$ & $>99 \mathbb{\int}$ & 62.9 & I & Skin & 9 & 0 & 333 \\
\hline Mean \pm SD & $24 \pm 7$ & $71 \pm 32$ & $>99$ & $>99$ & & $I \pm I$ & & $14 \pm 8$ & 0 & $1239 \pm 747$ \\
\hline Median & 24 & 56 & $>99$ & $>99$ & & I & & 11 & 0 & 905 \\
\hline
\end{tabular}

* Myeloid engraftment was defined by an absolute neutrophil count of at least 500 per cubic millimeter on three consecutive days, and platelet engraftment was defined by a platelet count of at least 50,000 per cubic millimeter without the need for transfusion for at least seven consecutive days. Chimerism was evaluated by fluorescence in situ hybridization for XY if the donor and the patient were different sexes. Otherwise, HLA typing or restriction-fragment-length polymorphism analysis was used. NE denotes not evaluated, and GI gastrointestinal.

$\dagger \alpha$-L-Iduronidase activity was measured in peripheral-blood leukocytes; the normal range is 30 to $70 \mathrm{nmol}$ per hour per milligram of protein.

$\uparrow$ The analysis of survival ended September 1, 2003.

$\int$ The value was obtained at six months.

\section{SURVIVAL}

As of September 1, 2003, a median of 905 days after transplantation (range, 333 to 2817), 17 of 20 patients were alive, for an overall event-free survival rate of 85 percent (Table 2 and Fig. 1C). One child died of idiopathic hyperammonemia on day 32 after transplantation, one of central nervous system hemorrhage related to cytomegalovirus infection on day 90 , and one, who received two cord-blood transplants, died of cytomegalovirus pneumonia 210 days after the first transplantation. Five children had serious adverse effects from which they recovered: hemolytic anemia in one, pulmonary hemorrhage in one, gallbladder hydrops in one, and ventriculoperitoneal-shunt infection in two. The median hospital stay was 39 days (range, 32 to 104).

\section{GENETIC EVALUATION}

Extremely low or undetectable concentrations of $\alpha$-L-iduronidase, as determined by immunoquantification, ${ }^{27}$ were found in all 20 children before transplantation, which is consistent with the phenotype of Hurler's syndrome. Although some common mutations have now been identified that are consistently associated with the phenotype, many children with severe disease have other rare or unidentified 

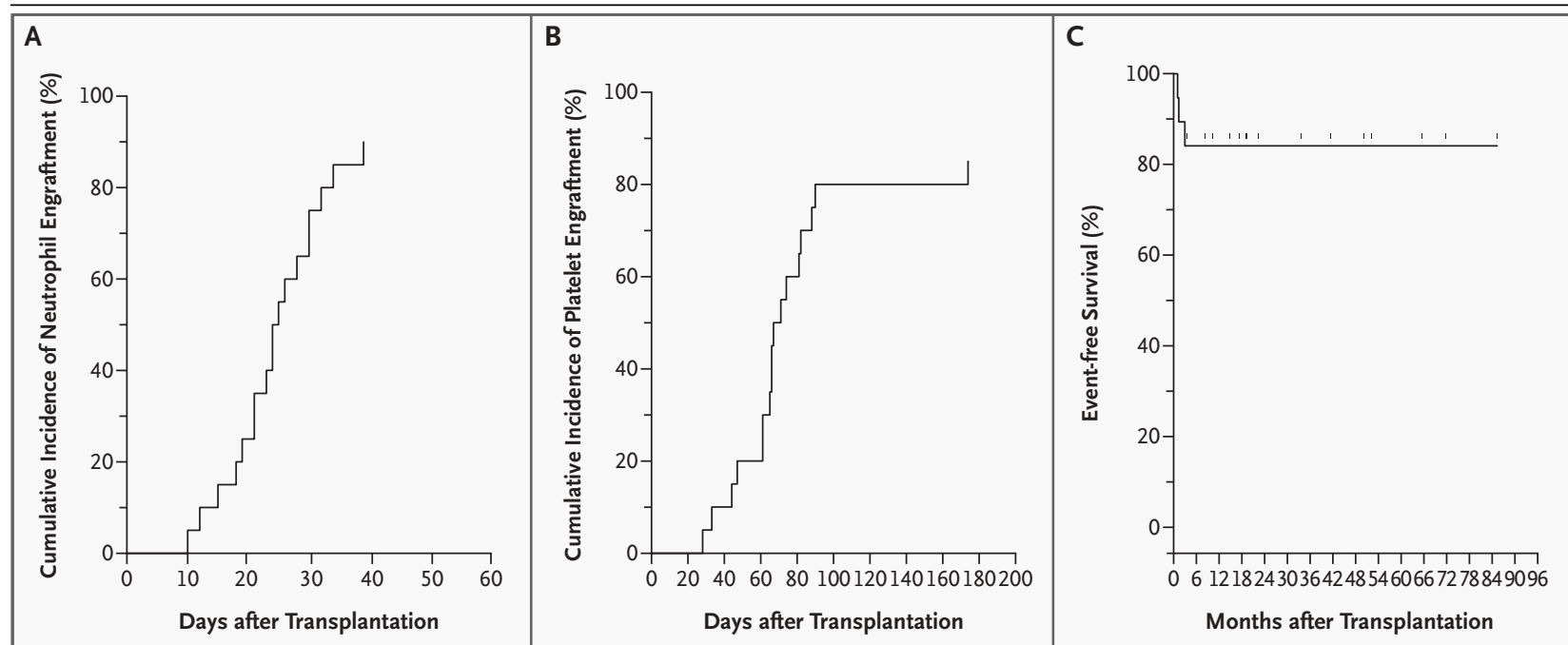

Figure 1. Cumulative Incidence of Neutrophil (Panel A) and Platelet (Panel B) Engraftment after Cord-Blood Transplantation and Kaplan-Meier Estimates of the Probability of Event-free Survival (Panel C).

In Panel A, myeloid engraftment was defined by an absolute neutrophil count of at least 500 per cubic millimeter on three consecutive days. The one patient who remained aplastic after the first cord-blood transplantation received a second cord-blood transplant on day 63 . Myeloid engraftment occurred on day 26 after the second transplantation. In Panel B, platelet engraftment was defined by a platelet count of at least 50,000 per cubic millimeter without the need for transfusion for at least seven consecutive days. In Panel $\mathrm{C}$, event-free survival was defined by survival with full (greater than 99 percent) donor chimerism. Tick marks indicate the most recent follow-up visit for each patient.

mutations. Two children in our series have been identified as homozygotes and seven as compound heterozygotes for common mutations associated with the severe phenotype. Two previously unreported mutations have been identified in two other patients.

\section{FOLLOW-UP}

All children were evaluated serially to document the late effects of cord-blood transplantation on Hurler's syndrome. Longitudinal growth was closely monitored, and within one year after transplantation, growth velocity was normal in the majority of patients and remained so (Fig. 2). Four of the children have required spinal fusion for kyphosis, six have had a spontaneous decrease in the degree of kyphosis after transplantation, kyphosis has not developed in two, and five have stable, mild kyphosis. One child has required hip surgery, and none have undergone carpal-tunnel or knee surgery to date. No child has had clinically significant cardiac dysfunction. All children had either stable or improved neurocognitive function after transplantation (Fig. 3A). Although the children quickly fell behind in development in the immediate post-transplantation period (slope $=0.56$ at 24 months), by 54 months of age the developmental slope had increased to 0.81 , and by 72 months they appeared to be gaining cognitive skills at a slightly slower rate (slope $=0.95$ ) than the mean for unaffected children (Fig. 3B).

\section{I S C USS I O N}

We describe the outcome in 20 children with Hurler's syndrome who received cord-blood transplants from unrelated donors after the administration of a chemotherapy-based preparative regimen. Eightyfive percent of the children survived with complete donor chimerism and normal peripheral-blood $\alpha$-L-iduronidase activity. In contrast, after bone marrow transplantation, graft failure has been reported in 28 to 37 percent of such patients, despite the use of total-body irradiation, ${ }^{9-11,13,14,17}$ and mixed chimerism with decreased $\alpha$-L-iduronidase activity has also been observed. ${ }^{10,11,13}$

The limited availability of donors is a major obstacle to bone marrow transplantation, with no suitable adult stem-cell donor identified in a timely fashion in more than 50 percent of patients. Banked umbilical-cord blood is prospectively HLA typed, screened for infections and other risk factors, and 


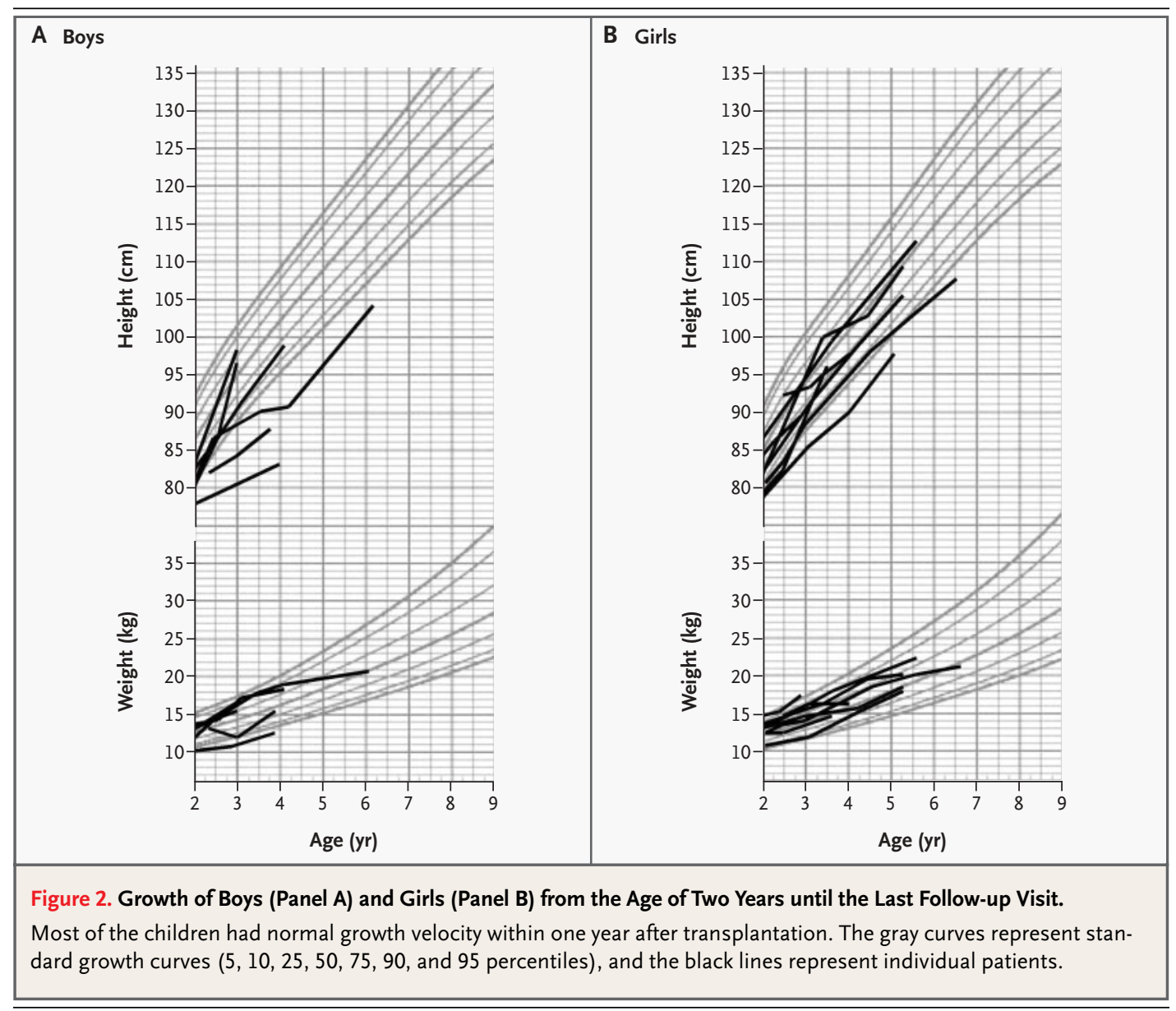

readily available for transplantation. In our study, the average time from the initiation of a search for a donor to the identification of a compatible unit of cord blood (including an assessment of $\alpha$-L-iduronidase activity) was 15 days. The time from the initiation of a search to the beginning of the conditioning regimen for transplantation was 41 days (31 days among patients who underwent transplantation after 2000). In a disease in which the time from diagnosis to definitive treatment may represent a crucial period in which to prevent further disease progression, a readily available source of stem cells is extremely desirable.

An additional advantage of the use of umbilical cord blood is that HLA matching does not have to be as close as that necessary for bone marrow grafts; this allows a donor to be identified for virtually all patients. Despite mismatching at one to three HLA loci in most donor-recipient pairs in our series, engraftment and immune reconstitution were complete, and the rates of acute and chronic GVHD were low. No deaths were attributable to GVHD, and none of the children had extensive chronic GVHD. By contrast, among children with Hurler's syndrome who receive bone marrow transplants from unrelated donors, the rates of GVHD have been reported to be 30 and 55 percent and to account for up to half of transplantation-associated mortality. ${ }^{11,17}$

Hematopoietic stem-cell transplantation arrests the progression of Hurler's syndrome, averting death from cardiac causes and liver disease, improving growth and development, and prolonging survival.3,4,7-17 Untreated children with Hurler's syndrome have severe growth failure by the age of two years, achieving a maximal height of $110 \mathrm{~cm} .{ }^{1}$ After cord-blood transplantation, the children in our study had normal growth velocities. Hurler's syndrome is associated with skeletal abnormalities, including kyphosis, hip dysplasia, and carpal tunnel syndrome, which cause serious complications and often require surgical correction. ${ }^{28,29}$ Previous data regarding the effect of hematopoietic stem-cell 
transplantation on skeletal abnormalities have been inconclusive. ${ }^{28,29}$ Some clear benefits have been recognized, such as the correction of odontoid dysplasia. ${ }^{30}$ In our series, five children required orthopedic intervention, whereas the remainder have had stabilization or regression of bony disease after transplantation, obviating the need for surgical intervention. Since the median age of these children is currently 4.5 years (range, 11 months to 10 years), additional long-term follow-up is needed to determine the full effect of cord-blood transplantation on the progression of the skeletal manifestations of Hurler's syndrome.

Fifteen of the 17 surviving children were serially evaluated by the neurodevelopmental team before and after transplantation. After the initial posttransplantation period of developmental delay, neurocognitive function stabilized or improved in all the children, and all have continued to gain skills. Three of the four oldest children have average-to-high IQs, although their genotypes and the results of protein analysis would predict them to have severe disease with rapid neurocognitive decline. Although results at 54 months were available for only four patients (24 percent of the group) and are therefore inconclusive, there was a trend toward increasing cognitive skills, with the mean scores of the sample falling within the normal range by 66 months of age.

Enzyme-replacement therapy with intravenous $\alpha$-L-iduronidase has ameliorated some manifestations of disease in patients older than six years who were less severely affected than our patients. ${ }^{31,32}$ Such patients form nonneutralizing antibodies that do not appear to interfere with the efficacy of treatment. ${ }^{33}$ Enzyme-replacement therapy is now being tested in limited numbers of more severely affected infants and younger children. Since the enzyme is unlikely to be able to cross the blood-brain barrier, transplantation therapy will continue to be used in children with Hurler's syndrome. Because of possible clinical gains with earlier exposure to enzyme, it is tempting to consider instituting enzyme-replacement therapy in patients with Hurler's syndrome while they are being prepared for transplantation. However, it is difficult to predict the nature of the antibody response and its possible influence on the efficacy of transplantation. Therefore, the pretransplantation use of enzyme-replacement therapy in the most severely affected patients with Hurler's syndrome should be tested in a controlled clinical trial and used with caution.

The children in this series underwent cord-blood

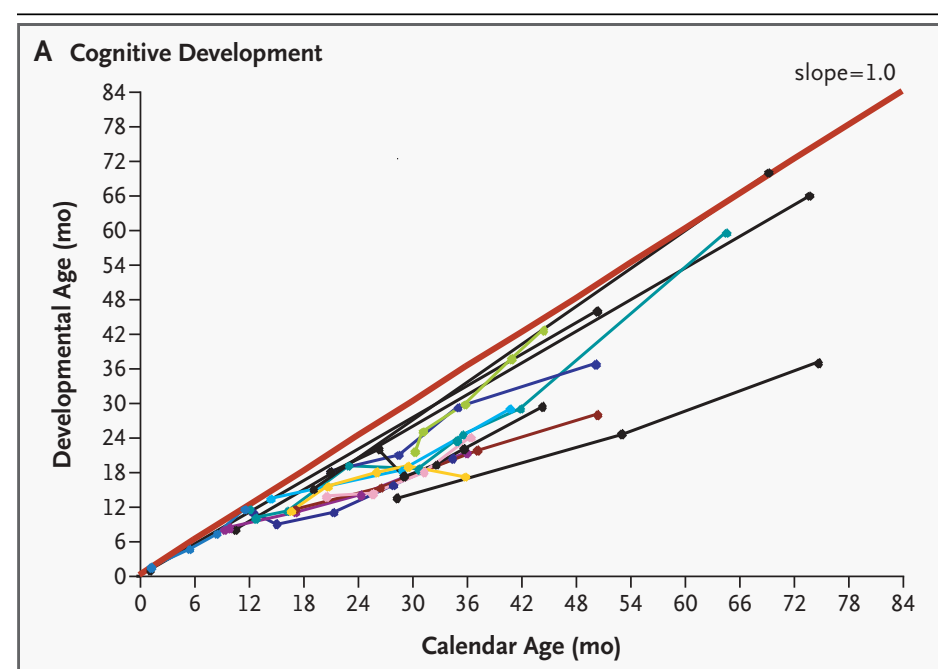

B Cognitive Development

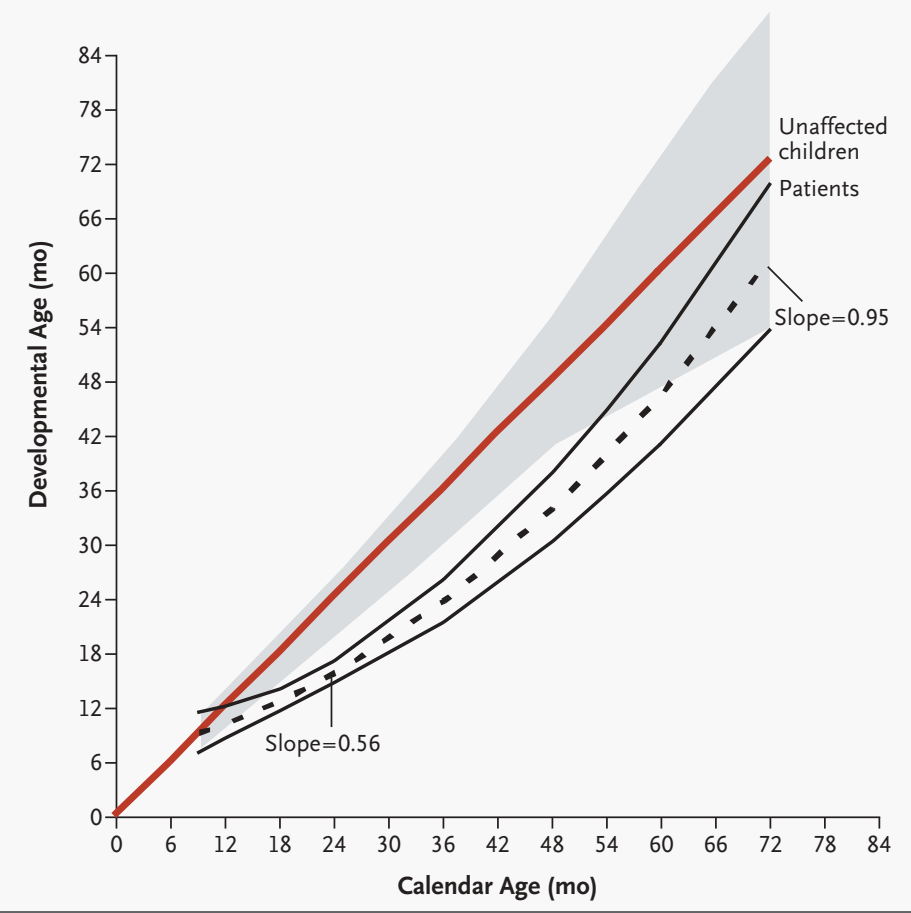

Figure 3. Neurocognitive Performance of Children with Hurler's Syndrome after Cord-Blood Transplantation (Panel A) and as Compared with That of Unaffected Children (Panel B).

We used age-equivalent scores for comparisons and to monitor the children's developmental progress. Panel A shows the cognitive trajectories achieved by plotting developmental age against chronologic age for each child over time. A slope of 1.0 (the straight red line) indicates normal developmental velocity. Panel $B$ shows the mean cognitive growth curve for all surviving patients plotted against the mean typical cognitive growth curve for unaffected children. The two thin black lines indicate the 95 percent confidence interval for the patients. The shaded area indicates the variability $( \pm 2 S D)$ in typical cognitive development. Only two of the patients (three observations) had data recorded before six months of age, and these observations were not included in the final analysis, because they could have overly influenced the estimates. 
transplantation at a median age of 16 months. In previous studies of bone marrow transplantation in patients with Hurler's syndrome, the median age was older - 19 to 24 months.9,11,13,14 Children who undergo transplantation at a younger age may derive more benefit, regardless of the source of the stem cells. Additional studies are needed to determine whether the positive outcomes in this study are related to the stem-cell source, the age at transplantation, or both.

In summary, we found that hematopoietic stemcell transplantation with banked cord blood from partially HLA-matched, unrelated donors favorably altered the natural history of Hurler's syndrome. Engraftment and full donor chimerism were achieved and maintained without the use of radiation therapy. The incidence of acute GVHD was low, and extensive chronic GVHD did not occur. Donors were readily and rapidly available. The overall event-free survival rate was 85 percent after a median follow-up of more than two years. Although long-term followup is needed to determine the full effect of cordblood transplantation on the natural history of Hurler's syndrome, patients appear to derive important benefits from this therapy. It may prove to be a therapeutic option for young patients with Hurler's syndrome who lack an HLA-matched, related bone marrow donor who is not a carrier of the disease.

Supported in part by the National Heart, Lung, and Blood Institute of the National Institutes of Health through the enrollment of patients in the Cord Blood Transplantation Study.

We are indebted to the inpatient and outpatient nursing staffs, physicians, and nurse practitioners of the Pediatric Stem Cell Transplant Program at Duke University Medical Center for caring for the patients; to the staff of the pediatric stem-cell laboratory for processing the units of umbilical-cord blood; to Dr. Robert Fitch of Pediatric Orthopedics at Duke University Medical Center for providing orthopedic care; and to the referring physicians and parents of the children for allowing us to treat them and study the consequences of umbilical-cord blood transplantation.
REFEREN CES

1. Neufeld EF, Muenzer J. The mucopolysaccharidoses. In: Scriver CR, Beaudet AL, Sly WS, Valle D, eds. The metabolic \& molecular bases of inherited disease. 8th ed. Vol. 3. New York: McGraw-Hill, 2001: 3421-52.

2. Resnick JM, Krivit W, Snover DC, et al. Pathology of the liver in mucopolysaccharidosis: light and electron microscopic assessment before and after bone marrow transplantation. Bone Marrow Transplant 1992; 10:273-80.

3. Hobbs JR, Hugh-Jones K, Barrett AJ, et al. Reversal of clinical features of Hurler's disease and biochemical improvement after treatment by bone-marrow transplantation. Lancet 1981;2:709-12.

4. Braunlin EA, Rose AG, Hopwood JJ Candel RD, Krivit W. Coronary artery patency following long-term successful engraftment 14 years after bone marrow transplantation in the Hurler syndrome. Am J Cardiol 2001;88:1075-7.

5. Vinallonga X, Sanz N, Balaguer A, Miro L, Ortega JJ, Casaldaliga J. Hypertrophic cardiomyopathy in mucopolysaccharidoses: regression after bone marrow transplantation. Pediatr Cardiol 1992;13:107-9.

6. Summers CG, Purple RL, Krivit W, et al Ocular changes in the mucopolysaccharidoses after bone marrow transplantation: a preliminary report. Ophthalmology 1989 ; 96:977-85.

7. Shapiro EG, Lockman LA, Balthazor M, Krivit W. Neuropsychological outcomes of several storage diseases with and without bone marrow transplantation. J Inherit Metab Dis 1995;18:413-29.

8. Krivit W, Peters C, Shapiro EG. Bone marrow transplantation as effective treatment of central nervous system disease in globoid cell leukodystrophy, metachromatic leukodystrophy, adrenoleukodystro phy, mannosidosis, fucosidosis, aspartylglucosaminuria, Hurler, Marteaux-Lamy, and Sly syndromes, and Gaucher disease type III. Curr Opin Neurol 1999;12:167-76.

9. Krivit W, Henslee-Downey J, Klemperer M, et al. Survival in Hurler's disease following bone marrow transplantation in 84 patients. Bone Marrow Transplant 1995;15: Suppl 1:S182-S185.

10. Whitley CB, Belani KG, Chang PN, et al. Long-term outcome of Hurler syndrome following bone marrow transplantation. Am Med Genet 1993;46:209-18.

11. Peters C, Balthazor M, Shapiro EG, et al. Outcome of unrelated donor bone marrow transplantation in 40 children with Hurler syndrome. Blood 1996;87:4894-902.

12. Peters C, Shapiro EG, Krivit W. Hurler syndrome: past, present, and future. J Pediatr 1998;133:7-9.

13. Guffon N, Souillet G, Maire I, StraczekJ, Guibaud P. Follow-up of nine patients with Hurler syndrome after bone marrow transplantation. J Pediatr 1998;133:119-25.

14. Peters C, Shapiro EG, Anderson J, et al. Hurler syndrome. II. Outcome of HLA-genotypically identical sibling and HLA-haploidentical related donor bone marrow transplantation in fifty-four children. Blood 1998 ; 91:2601-8.

15. Cowan M. Bone marrow transplantation for the treatment of genetic diseases. Clin Biochem 1991;24:375-81.

16. Whitley CB, Ramsay NK, KerseyJH, Krivit W. Bone marrow transplantation for Hurl- er syndrome: assessment of metabolic correction. Birth Defects Orig Artic Ser 1986; 22:7-24.

17. Fleming DR, Henslee-Downey PJ, Ciocci $\mathrm{G}$, et al. The use of partially HLA-mismatched donors for allogeneic transplantation in patients with mucopolysaccharidosis-I. Pediatr Transplant 1998;2:299-304.

18. Kurtzberg J, Laughlin M, Graham ML, et al. Placental blood as a source of hematopoietic stem cells for transplantation into unrelated recipients. N Engl J Med 1996; 335:157-66.

19. Gluckman E, Broxmeyer HE, Auerbach $\mathrm{AD}$, et al. Hematopoietic reconstitution in a patient with Fanconi's anemia by means of umbilical-cord blood from an HLA-identical sibling. N Engl J Med 1989;321:1174-8.

20. Rubinstein P, Rosenfield RE, Adamson JW, Stevens CE. Stored placental blood for unrelated bone marrow reconstitution. Blood 1993;81:1679-90.

21. Wenger DA, Williams C. Screening for lysosomal disorders. In: Hommes FA, ed. Techniques in diagnostic human biochemical genetics: a laboratory manual. New York: Wiley-Liss, 1991:587-617.

22. deGasperi R, Raghavan SS, Gama Sosa MA, et al. Measurement from normal umbilical cord blood of four lysosomal enzyme activities: $\alpha$-L-iduronidase (Hurler), galactocerebrosidase (globoid cell leukodystrophy), arylsulfatase A (metachromatic leukodystrophy), arylsulfatase B (MaroteauxLamy). Bone Marrow Transplant 2000;25: 541-4.

23. Rubinstein P, Dobrila L, Rosenfield RE, et al. Processing and cryopreservation of placental/umbilical cord blood for unrelat- 
ed bone marrow reconstitution. Proc Natl Acad Sci U S A 1995;92:10119-22.

24. Jacobson P, PrakJ, DeFor TE, et al. Oral busulfan pharmacokinetics and engraftment in children with Hurler syndrome and other inherited metabolic storage diseases undergoing hematopoietic stem cell transplantation. Bone Marrow Transplant 2001;27:85561.

25. Przepiorka D, Weisdorf D, Martin P, et al. 1994 Consensus Conference on Acute GVHD Grading. Bone Marrow Transplant 1995; $15: 825-8$

26. Gooley TA, Leisenring W, Crowley J, Storer BE. Estimation of failure probabilities in the presence of competing risks: new representations of old estimators. Stat Med 1999;18:695-706.
27. Ashton LJ, Brooks DA, McCourt PA, Muller VJ, Clements PR, Hopwood JJ. Immunoquantification and enzyme kinetics of alpha-L-iduronidase in cultured fibroblasts from mucopolysaccharidosis type I patients. Am J Hum Genet 1992;50:787-94.

28. Masterson EL, Murphy PG, O’Meara A Moore DP, Dowling FE, Fogarty EE. Hip dysplasia in Hurler's syndrome: orthopaedic management after bone marrow transplantation. J Pediatr Orthop 1996;16: 731-3.

29. Odunusi E, Peters C, Krivit W, Ogilvie J. Genu valgum deformity in Hurler syndrom after hematopoietic stem cell transplantation: correction by surgical intervention. J Pediatr Orthop 1999;19:270-4.

30. Hite SH, Peters C, Krivit W. Correction of odontoid dysplasia following bone-marrow transplantation and engraftment (in Hurler syndrome MPSH 1). Pediatr Radiol 2000;30:464-70.

31. Wraith JE. Enzyme replacement therapy in mucopolysaccharidosis type I: progress and emerging difficulties. J Inherit Metab Dis 2001;24:245-50.

32. Kakkis ED, Muenzer J, Tiller GE, et al. Enzyme-replacement therapy in mucopolysaccharidosis I. N Engl J Med 2001;344:1828.

33. Kakavanos R, Turner CT, Hopwood JJ, Kakkis ED, Brook DA. Immune tolerance after long-term enzyme-replacement therapy among patients who have mucopolysaccharidosis I. Lancet 2003;361:1608-13.

Copyright (c) 2004 Massachusetts Medical Society.

FULL TEXT OF ALL JOURNAL ARTICLES ON THE WORLD WIDE WEB

Access to the complete text of the Journal on the Internet is free to all subscribers. To use this Web site, subscribers should go to the Journal's home page (www.nejm.org) and register by entering their names and subscriber numbers as they appear on their mailing labels. After this one-time registration, subscribers can use their passwords to log on for electronic access to the entire Journal from any computer that is connected to the Internet. Features include a library of all issues since January 1993 and abstracts since January 1975, a full-text search capacity, and a personal archive for saving articles and search results of interest. All articles can be printed in a format that is virtually identical to that of the typeset pages. Beginning six months after publication, the full text of all Original Articles and Special Articles is available free to nonsubscribers who have completed a brief registration. 